\title{
Parental bonding in males with adjustment disorder and hyperventilation syndrome
}

For-Wey Lung ${ }^{1,2,6^{*}}$, Ting-Hsuan Lee Le $^{3,4}$ and Mei-Feng Huang ${ }^{5}$

\begin{abstract}
Background: The purpose of the study was to identify the style of parental bonding and the personality characteristics that might increase the risk of hyperventilation and adjustment disorder.

Methods: A total of 917 males were recruited, 156 with adjustment disorder and hyperventilation syndrome $(\mathrm{AD}+\mathrm{HY}), 273$ with adjustment disorder without hyperventilation syndrome (AD-HY), and 488 healthy controls. All participants completed the Parental Bonding Instrument, Eysenck Personality Questionnaire, and Chinese Health Questionnaire.

Results: Analysis using structural equation models identified a pathway relationship in which parental bonding affected personality characteristics, personality characteristics affected mental health condition, and mental health condition affected the development of hyperventilation or adjustment disorder. Males with AD-HY perceived less paternal care, and those with AD + HY perceived more maternal protection than those with adjustment disorder and those in the control group. Participants with $\mathrm{AD}-\mathrm{HY}$ were more neurotic and less extroverted than those with $A D+H Y$. Both groups showed poorer mental health than the controls.

Conclusions: Although some patients with hyperventilation syndrome demonstrated symptoms of adjustment disorder, there were different predisposing factors between the two groups in terms of parental bonding and personality characteristics. This finding is important for the early intervention and prevention of hyperventilation and adjustment disorder.
\end{abstract}

Keywords: Adjustment disorder, Hyperventilation syndrome, Parental attachment, Multitrait methodology, Hierarchical structural equation model

\section{Background}

Parental attachment and premorbid personality traits play an important role in shaping the developmental trajectory of an individual and influence their ability to adjust to stressful events [1-3]. In particular, problems with parental attachment during childhood are considered to be a predisposing factor for the onset of many psychiatric conditions, such as anxiety, depressive states, and maladjustment behaviors [4-8].

Hyperventilation syndrome refers to various somatic and psychological symptoms that appear to be a consequence of episodes of hyperventilation with no known organic basis [9]. It was identified first by DaCosta in 1871

\footnotetext{
* Correspondence: forwey@seed.net.tw

'Songde Branch, Taipei City Hospital, Taipei, Taiwan

2Department of Psychiatry, National Defense Medical Center, Taipei, Taiwan

${ }^{6}$ Department of Neurology, Kaohsiung Medical University, Kaohsiung, Taiwan

Full list of author information is available at the end of the article
}

in military personnel [10]. A study of functional somatic complaints, including hyperventilation syndrome, found that adolescents with these complaints have poor psychosocial adjustment to negative life events [11]. It has been found that this is related to overwhelming anxiety, distressful events, military life, and other situations [12]. Moreover, people with hyperventilation syndrome tend to have high levels of obsessional behavior, together with difficulty handling everyday stress [13]. The diagnostic category of hyperventilation syndrome remains unknown; however, it has been described as a type of maladjustment behavior, and it can be comorbid with emotional problems [14].

The term adjustment disorder refers to patients who have developed clinically significant emotional or behavioral symptoms; these symptoms dissipate eventually, once the stressor has been terminated [15]. It has been argued that adjustment disorder does not conform to

\section{Biomed Central}


the criteria for specific symptoms, because approximately $35 \%$ of patients with adjustment disorder have comorbidity with other Axis I and II diagnoses [16,17]. In addition, the diagnosis of adjustment disorder is difficult to determine, and it has been described as a 'waste basket diagnosis'.

It is thought that hyperventilation syndrome might be related to adjustment disorder. In addition to stress, both hyperventilation syndrome and adjustment disorder have been found to be associated with parental bonding and personality characteristics [1,14,18]. In these earlier studies, male patients with adjustment disorder all showed signs of parental overprotection, regardless of whether they showed symptoms of hyperventilation. In addition, those with more introverted and neurotic personality characteristics were more likely to develop adjustment disorder [14,18]. Patients who report a greater degree of paternal overprotection and less parental care are also more likely to develop adjustment disorder [1]. Thus, parental bonding and personality characteristics have a major effect on hyperventilation syndrome and adjustment disorder. In particular, attachment insecurity leads to an increased risk of disease through a range of mechanisms, which include increased susceptibility to stress, increased use of external regulators of dysphoric affect, and alterations in help-seeking behavior $[19,20]$. The differences between patients with adjustment disorder, those with hyperventilation syndrome, and male individuals without psychiatric illnesses are unclear; nevertheless, understanding the relationship between the two conditions is important.

Hence, the purpose of the study reported herein was to identify the style of parental bonding and the personality characteristics that might increase the risk of hyperventilation syndrome and adjustment disorder. Patients with hyperventilation syndrome, those with adjustment disorder, and male controls were compared to determine the differences between the groups, to provide information for the development of early intervention and prevention programs.

\section{Methods}

\section{Participants}

Ethical approval was obtained from the institutional review board at Kaohsiung Armed Forces General Hospital in southern Taiwan. The participants gave their consent after they were informed of the details of the study. The study population included 273 male military conscripts who had been diagnosed with adjustment disorder by a psychiatrist at a teaching hospital in southern Taiwan. An additional 156 male conscripts with adjustment disorder who visited the emergency room at the same hospital because of an episode of acute hyperventilation were also recruited. First, all participants who attended the emergency room underwent several clinical assessments, which included taking a history, a physical examination, noninvasive blood pressure measurement, 12-lead ECG, continuous ECG monitoring, pulse oximetry, standard blood tests, and chest-X ray. These assessments were performed by physicians in the emergency department. Second, arterial blood was withdrawn to measure the partial pressure of carbon dioxide $\left(\mathrm{PCO}_{2}\right)$ (see Table 1 ). The diagnosis of acute hyperventilation was made by two internal medicine specialists on clinical grounds, on the basis of the patient history, clinical observation, physical examination, and biochemical tests. Subsequently, a psychiatrist was informed so that they could take over the care of the patient after organic medical diseases had been ruled out. Finally, all patients with hyperventilation syndrome were interviewed by a senior psychiatrist, and those who were also diagnosed with adjustment disorder were assigned to the AD + HY group.

All participants in the adjustment disorder with hyperventilation $(A D+H Y)$ group and in the adjustment disorder without hyperventilation (AD-HY) group were admitted to a teaching hospital for at least one week to verify the diagnosis. The patients were interviewed by a senior psychiatrist with reference to the Diagnostic and Statistical Manual of Mental Disorders, Fourth Edition (DSM-IV) [15]. All of the participants had presented without any pre-existing mental disorders. No participant who had any clinical evidence of physical illness, panic disorder, or other psychiatric disorders included in the International Classification of Diseases, 10th Edition (ICD-10) [21] was referred. A one-year cohort study was also used to verify the stability of the diagnosis of adjustment disorder.

A control group composed of 488 male conscripts who were at the same military base as the case group and had no experience of hyperventilation syndrome or any other physical or psychiatric illness was also recruited.

\section{Materials}

A self-report questionnaire, which included demographic information, the Parental Bonding Instrument (PBI), the Eysenck Personality Questionnaire (EPQ), and the Chinese Health Questionnaire (CHQ), was used. The demographic data collected included the patient's age, marital status, and education.

Table 1 The $\mathrm{pH}, \mathrm{O}_{2}$, and $\mathrm{CO}_{2}$ values in participants with hyperventilation syndrome

\begin{tabular}{lcccc}
\hline & M & SD & Min & Max \\
\hline $\mathrm{pH}$ & 7.49 & 0.02 & 7.36 & 7.65 \\
$\mathrm{O}_{2}$ value & 57.31 & 7.93 & 21.9 & 130.1 \\
$\mathrm{CO}_{2}$ value & 29.76 & 2.02 & 13.7 & 51.6 \\
\hline
\end{tabular}




\section{Parental bonding instrument (PBI)}

Parker, Tupling, and Brown developed the PBI in 1979 [22]. The PBI was designed as a refined self-report measure of fundamental dimensions of care and protection for each parent. The Chinese version of the PBI was modified by Shu, Lo, and Lung [23]. The questionnaire instructs respondents to rate "how true" they judge each of the 25 items as a description of their mother's and (separately) father's behaviors toward them during the first 16 years of life. The rating options are "very much like", "moderately like", "moderately unlike" and "very much unlike", which generate scores of $3,2,1$, and 0 , respectively. The Cronbach alpha value for the PBI is $0.65-0.73$, and test-retest reliability is $0.66-0.88$ [23].

\section{Eysenck personality questionnaire (EPQ)}

Eysenck and Eysenck developed the EPQ [24]. It consists of four subscales: psychoticism, extroversion, neuroticism, and lying. The Chinese version of the EPQ was modified by $\mathrm{Lu}$ [25] and includes 25 items, which comprise two subscales: extroversion (14 items) and neuroticism (11 items). A Cronbach alpha value of 0.90 and good validity were demonstrated by $\mathrm{Lu}$ [25].

\section{Chinese health questionnaire (CHQ)}

Cheng and Williams [26] designed the CHQ. It was derived from a Chinese translation of the General Health Questionnaire [27,28], with culturally relevant items added to a primary item pool. This item pool was treated with discriminant function analysis to select a subset of 12 items. A simple scoring method of 0-0-1-1, with rating options of "not at all", "same as usual", "more than usual", and "a lot more than usual", is applied to the CHQ. The optimum cutoff point (the best compromise between high sensitivity and a low false-positive rate) for the $\mathrm{CHQ}$, as determined using the receiver operating characteristic (ROC) curve, is 3/4 [29,30]. The internal consistency of the CHQ is indicated by an alpha coefficient of 0.79 , as demonstrated by Cheng et al. [29].

\section{Statistical analysis}

The data were analyzed using the software package SPSS 17.0 for Windows (SPSS, Chicago, IL), and the structural equation model (SEM) was analyzed using the AMOS 7.0 statistical software package (SPSS, Chicago, IL). All variables were analyzed using one-way analysis of variance (ANOVA) to compare the differences among the three groups. In addition, Bonferroni post hoc multiple comparisons were used to compare each pair group in terms of any statistically significant variables. The SEM techniques made use of all the information that was provided by the regression techniques in a path analysis. If the SEM resulted in a $\mathrm{p}$ value greater than 0.05 , an adjusted goodness-of-fit index (AGFI) greater than
0.9 , and a root mean square error of approximation (RMSEA) less than 0.08, this indicated that the null model corresponded to the real structure.

\section{Results}

The demographic distribution of the three groups those with adjustment disorder and hyperventilation $(\mathrm{AD}+\mathrm{HY})$, those with adjustment disorder alone (AD$\mathrm{HY}$ ), and controls - was as follows. All participants were male; the mean age of the $\mathrm{AD}+\mathrm{HY}$ group was 21.12 $(\mathrm{SD}=1.98)$ years, for the $\mathrm{AD}-\mathrm{HY}$ group it was 21.86 $(\mathrm{SD}=2.36)$ years, and for the controls $22.61(\mathrm{SD}=2.18)$ years. In terms of the average years of education received by the participants, all had graduated from high school; the $\mathrm{AD}+\mathrm{HY}$ group had received a mean of $12.92(\mathrm{SD}=$ 2.29) years of education, the $\mathrm{AD}-\mathrm{HY}$ group a mean of $13.56(\mathrm{SD}=2.87)$ years, and the controls $13.94(\mathrm{SD}=.61)$ years. There were statistically significant differences with respect to age $(\mathrm{F}=29.91, p<0.001)$ and level of education $(\mathrm{F}=8.93, p<0.001)$ among the three groups; in subsequent analyses, these factors were controlled for.

\section{One-way ANOVA}

The comparisons of parental bonding, personality characteristics, and mental health condition among the three groups are shown in Table 2. The results of ANOVA showed statistically significant differences among the three groups with respect to all dimensions measured. The differences in paternal and maternal care among the three groups, as assessed with the PBI, were statistically significant $\left(\mathrm{F}_{\text {paternal care }}=73.02, p<0.001 ; \mathrm{F}_{\text {maternal care }}=\right.$ $34.29, p<0.001)$. For paternal care, in the $\mathrm{AD}+\mathrm{HY}$ group the mean score was $19.07(\mathrm{SD}=6.88)$, and in the $\mathrm{AD}-\mathrm{HY}$ group it was $16.59(\mathrm{SD}=7.48)$, compared with $22.86(\mathrm{SD}=6.78)$ in the controls. For maternal care, in the $\mathrm{AD}+\mathrm{HY}$ group the mean score was $22.75(\mathrm{SD}=$ $6.04)$, and in the $\mathrm{AD}-\mathrm{HY}$ group it was $21.34(\mathrm{SD}=7.63)$, compared with $25.42(\mathrm{SD}=6.39)$ in the controls. The differences in paternal and maternal protection among the three groups were also statistically significant $\left(\mathrm{F}_{\text {paternal }}\right.$ protection $=66.49, p<0.001 ; \mathrm{F}_{\text {maternal }}$ protection $=$ 48.76, $p<0.001)$. For paternal protection in the $\mathrm{AD}+$ HY group the mean score was $14.47(\mathrm{SD}=5.54)$, and in the AD-HY group it was $15.50(\mathrm{SD}=6.20)$, compared with $10.68(\mathrm{SD}=5.81)$ in the controls. For maternal protection in the AD + HY group the mean score was 14.72 $(\mathrm{SD}=6.54)$, and in the $\mathrm{AD}-\mathrm{HY}$ group it was $15.29(\mathrm{SD}=$ 6.89), compared with $10.92(\mathrm{SD}=6.06)$ in the controls. Using Bonferroni post hoc tests, between-group comparisons showed that there were no significant differences between the $\mathrm{AD}+\mathrm{HY}$ and $\mathrm{AD}-\mathrm{HY}$ groups in terms of the parental bonding dimensions of maternal care, maternal protection, and paternal protection $(\mathrm{MD}=1.41$, 
Table 2 Parental attachment, personality characteristics, and mental health status of patients with $A D+H Y$, with AD-HY, and controls $(\mathrm{N}=917)$

\begin{tabular}{|c|c|c|c|c|c|}
\hline Factors & $\frac{\frac{A D+H Y}{(n=156)}}{\text { Mean (SD) }}$ & $\frac{\frac{A D-H Y}{(n=273)}}{\text { Mean (SD) }}$ & $\frac{\frac{\text { Control }}{(n=488)}}{\text { Mean (SD) }}$ & ANOVA & Bonferroni post hoc test \\
\hline \multicolumn{6}{|c|}{ Personality characteristics } \\
\hline \multirow[t]{3}{*}{ Extroversion } & $6.08(4.23)$ & $4.47(3.94)$ & $9.31(3.50)$ & $F=155.53$ & Hyperventilation $<$ Control; MD $=-0.32, p<0.001$ \\
\hline & & & & $p<.001$ & Hyperventilation > Adjustment; $\mathrm{MD}=1.61, p<0.001$ \\
\hline & & & & & Adjustment $<$ Control; $\mathrm{MD}=-4.85, p<0.001$ \\
\hline \multirow[t]{3}{*}{ Neuroticism } & $7.86(3.08)$ & $9.26(2.34)$ & $3.00(3.04)$ & $F=473.74$ & Hyperventilation $>$ Control; $\mathrm{MD}=4.86, p<0.001$ \\
\hline & & & & $p<.001$ & Hyperventilation $<$ Adjustment; $\mathrm{MD}=-1.39, p<0.001$ \\
\hline & & & & & Adjustment $>$ Control; MD $=6.26, p<0.001$ \\
\hline \multicolumn{6}{|l|}{ Parental bonding } \\
\hline \multirow[t]{3}{*}{ Maternal care } & $22.75(6.04)$ & $21.34(7.63)$ & $25.42(6.39)$ & $F=34.29$ & Hyperventilation $<$ Control; MD $=-2.67, p<0.001$ \\
\hline & & & & $p<.001$ & Hyperventilation $>$ Adjustment; $\mathrm{MD}=1.41, p=0.110$ \\
\hline & & & & & Adjustment $<$ Control; $\mathrm{MD}=-4.08, p<0.001$ \\
\hline \multirow[t]{3}{*}{ Maternal protection } & $14.72(6.54)$ & $15.29(6.89)$ & $10.92(6.06)$ & $F=48.76$ & Hyperventilation $>$ Control; $\mathrm{MD}=3.81, p<0.001$ \\
\hline & & & & $p<.001$ & Hyperventilation < Adjustment; $\mathrm{MD}=-0.56, p=1.00$ \\
\hline & & & & & Adjustment $>$ Control; $\mathrm{MD}=4.37, p<0.001$ \\
\hline \multirow[t]{3}{*}{ Paternal care } & $19.07(6.88)$ & $16.59(7.48)$ & $22.86(6.78)$ & $F=73.02$ & Hyperventilation $<$ Control; MD $=-3.79, p<0.001$ \\
\hline & & & & $p<.001$ & Hyperventilation > Adjustment; $\mathrm{MD}=2.48, p=0.001$ \\
\hline & & & & & Adjustment $<$ Control; $\mathrm{MD}=-6.27, p<0.001$ \\
\hline \multirow[t]{3}{*}{ Paternal protection } & $14.47(5.54)$ & $15.50(6.20)$ & $10.68(5.81)$ & $F=66.49$ & Hyperventilation $>$ Control; $\mathrm{MD}=3.79, p<0.001$ \\
\hline & & & & $p<.001$ & Hyperventilation < Adjustment; MD $=-1.03, p=2.47$ \\
\hline & & & & & Adjustment $>$ Control; $\mathrm{MD}=4.82, p<0.001$ \\
\hline \multirow[t]{3}{*}{ Mental health } & $6.62(3.51)$ & $7.45(3.49)$ & $1.00(1.88)$ & $F=574.44$ & Hyperventilation $>$ Control; $\mathrm{MD}=5.63, p<0.001$ \\
\hline & & & & $p<.001$ & Hyperventilation < Adjustment; MD $=-0.83, p=0.008$ \\
\hline & & & & & Adjustment $>$ Control; $\mathrm{MD}=6.46, p<0.001$ \\
\hline
\end{tabular}

$\mathrm{AD}+\mathrm{HY}$ : adjustment disorder with hyperventilation syndrome; AD-HY: adjustment disorder without hyperventilation syndrome; MD: mean difference.

$p=0.110 ; \mathrm{MD}=-0.56, p=1.000 ; \mathrm{MD}=-1.03, p=0.246)$. The results are shown in Table 2.

The mean score for extraversion in the $\mathrm{AD}+\mathrm{HY}$ group, as assessed with the EPQ, was 6.08 ( $\mathrm{SD}=4.23)$, and in the AD-HY group it was 4.47 ( $\mathrm{SD}=3.94)$, compared with $9.31(\mathrm{SD}=3.50)$ in the controls. The mean score for neuroticism in the $\mathrm{AD}+\mathrm{HY}$ group was 7.86 $(\mathrm{SD}=3.08)$, and in the AD-HY group it was $9.26(\mathrm{SD}=$ $2.34)$, compared with $3.00(\mathrm{SD}=3.04)$ in the controls. The differences in extraversion and neuroticism among three groups were statistically significant $\left(\mathrm{F}_{\text {extraversion }}=\right.$ 155.53, $\left.p<0.001 ; \mathrm{F}_{\text {neuroticism }}=473.74, p<0.001\right)$.

Furthermore, the mean score for mental health in the AD + HY group, as assessed with the CHQ, was 6.62 $(\mathrm{SD}=3.51)$, and in the AD-HY group it was $7.45(\mathrm{SD}=$ $3.49)$, compared with $1.00(\mathrm{SD}=1.88)$ in the controls. The difference in mental health among the three groups was statistically significant $(\mathrm{F}=574.44, p<0.001)$. Using Bonferroni post hoc tests, between-group comparisons showed that there were no significant differences between the $\mathrm{AD}+\mathrm{HY}$ and $\mathrm{AD}-\mathrm{HY}$ groups $(\mathrm{MD}=-0.83$, $p=0.008)$.

\section{Structural equation modeling}

SEM was used to investigate differences in the hierarchical pathways between parental bonding, personality characteristics, and mental health condition among the three groups. The analysis was carried out in three paired group models: AD-HY and controls in the first model (Figure 1a), AD + HY and controls in the second model (Figure 1b), and $\mathrm{AD}-\mathrm{HY}$ and $\mathrm{AD}+\mathrm{HY}$ in the third model (Figure 1c). Parsimonious models were developed, which meant that only statistically significant pathways were shown. All models showed a pathway relationship in which parental bonding affected personality characteristics, personality characteristics affected mental health condition, and mental health condition affected whether subjects developed adjustment disorder or hyperventilation, as shown in Figure 1. 


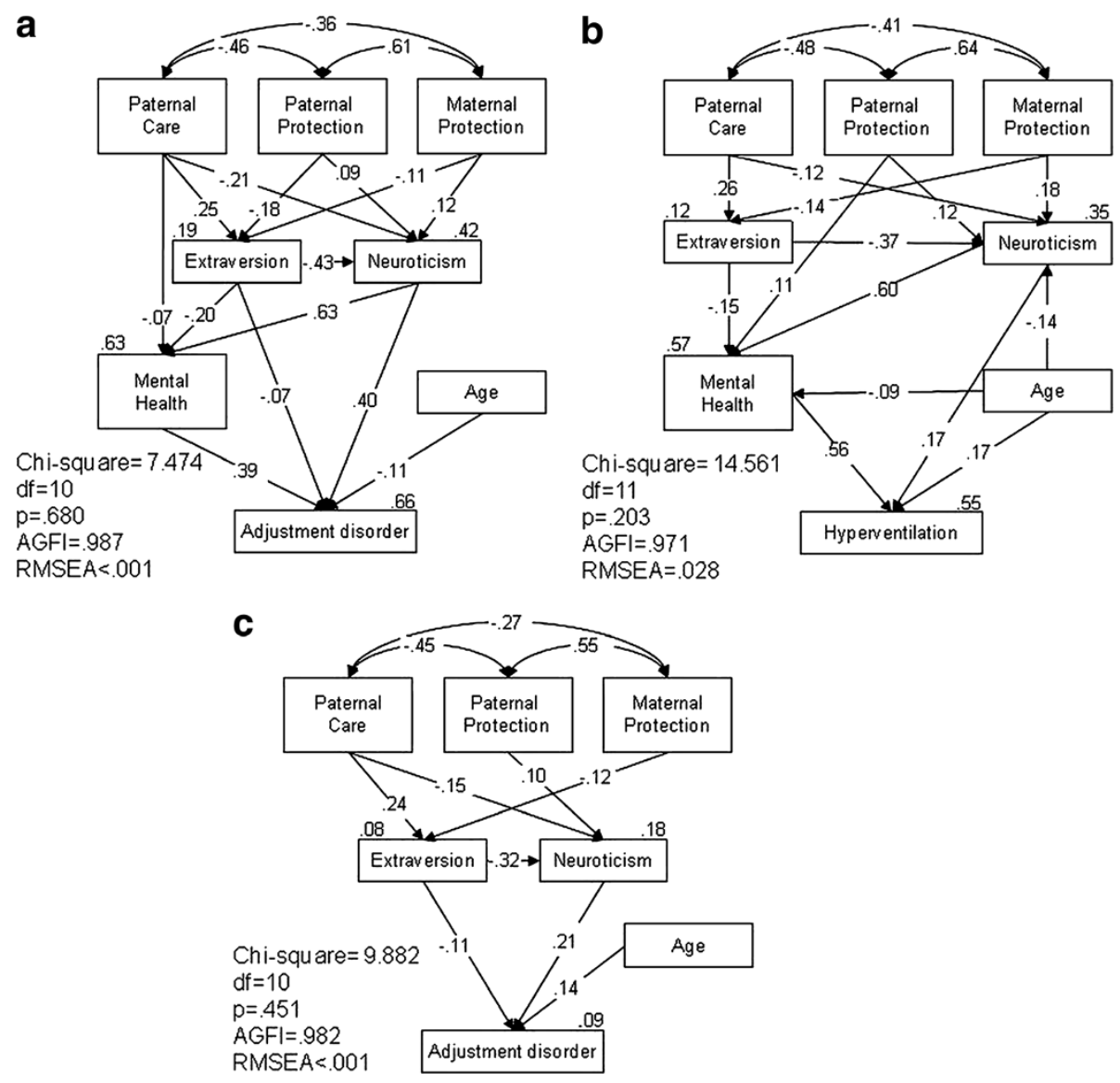

Figure 1 The parsimonious structural equation model (SEM) comparison between a) the AD-HY group and controls, b) the AD+HY group and controls, and c) the AD-HY and AD + HY groups with respect to parental attachment, personality characteristics, and mental health condition. AGFI: adjusted goodness-of-fit indices; RMSEA: root mean square error of approximation; AD + HY: adjustment disorder with hyperventilation syndrome; AD-HY: adjustment disorder without hyperventilation syndrome. a) group dummy variable of 1: AD-HY, 0 : control. b) group dummy variable of 1: $A D+H Y$, 0: control. c) group dummy variable of 1: $A D+H Y, 2: A D-H Y$.

The first parsimonious model, which compared ADHY and controls, resulted in a good fit, with a $p$ value of 0.680 (i.e., greater than 0.05), an AGFI of 0.987 (i.e., greater than 0.9), and an RMSEA of less than 0.001 (i.e., less than 0.5), as shown in Figure 1a. When fathers showed less care, their sons were less extroverted, more neurotic, and had poorer mental health $(\beta=0.25$, $p<0.001 ; \quad \beta=-0.21, \quad p<0.001 ; \quad \beta=-0.07, \quad p=0.016$, respectively). When parents were overprotective, their sons were less extroverted and more neurotic (father: $\beta=-0.18, \quad p<0.001 ; \quad \beta=0.09, \quad p=0.039 ; \quad$ mother: $\beta=-0.11, p=0.035 ; \beta=0.12, p=0.006$, respectively). In addition, participants who were less extroverted or more neurotic had poorer mental health and were more likely to develop adjustment disorder (extroversion: $\beta=-0.20$, $p<0.001 ; \beta=-0.07, p=0.023$; neuroticism: $\beta=0.63$, $p<0.001 ; \beta=0.40, p<0.001$, respectively). Finally, participants with poorer mental health or those who were younger were more likely to develop adjustment disorder
( $\beta=0.39, p<0.001 ; \beta=-0.11, p<0.001$, respectively). Extroversion, neuroticism, mental health condition, and adjustment disorder accounted for $19 \%, 42 \%, 63 \%$, and $66 \%$ of the variance, respectively.

The second model compared participants with $\mathrm{AD}+$ HY and the controls. The model resulted in a good fit, with a $p$ value of 0.203 , an AGFI of 0.971 , and an RMSEA of 0.028, as shown in Figure 1b. Those who had received less paternal care and maternal overprotection were less extroverted and more neurotic (father: $\beta=0.26$, $p<0.001 ; \quad \beta=-0.12, \quad p=0.013 ; \quad$ mother: $\beta=-0.14$, $p=0.006 ; \beta=0.18, p=0.001$, respectively). In the case of fathers who were overprotective, their sons were more neurotic and had poorer mental health $(\beta=0.12$, $p=0.029 ; \beta=0.11, p=0.002$, respectively). In addition, participants who were less extroverted had poorer mental health $(\beta=-0.15, p<0.001)$, and those who were more neurotic had poorer mental health and a greater likelihood of developing adjustment disorder and 
hyperventilation $(\beta=0.60, p<0.001 ; \beta=0.17, p<0.001$, respectively). Those with poorer mental health were also at a higher risk of developing adjustment disorder and hyperventilation ( $\beta=0.56, p<0.001$ ). Extroversion, neuroticism, mental health condition, and hyperventilation accounted for $12 \%, 35 \%, 57 \%$, and $55 \%$ of the variance, respectively.

The last model compared participants with $\mathrm{AD}+\mathrm{HY}$ and those with $\mathrm{AD}-\mathrm{HY}$. The model resulted in a $p$ value of 0.451, an AGFI of 0.982, and an RMSEA of less than 0.001, which indicated a good fit, as shown in Figure 1c. The dummy variable for group was 1 for those with $\mathrm{AD}+\mathrm{HY}$ and 2 for those with AD-HY. Fathers who showed less care had sons who were less extroverted and more neurotic $(\beta=0.24, \quad p<0.001 ; \beta=-0.15$, $p=0.003$, respectively). When fathers were overprotective, their sons were more neurotic $(\beta=0.10, p=0.043)$, and when mothers were overprotective, their sons were less extroverted $(\beta=-0.12, p=0.014)$. Compared with those with $\mathrm{AD}+\mathrm{HY}$, those with $\mathrm{AD}-\mathrm{HY}$ were less extroverted and more neurotic $(\beta=-0.11, p=0.024$; $\beta=0.21, p<0.001$, respectively). Extroversion, neuroticism, and adjustment disorder accounted for $8 \%, 18 \%$, and $9 \%$ of the variance, respectively.

\section{Discussion}

Use of one-way ANOVA showed significant differences in all dimensions among the three groups; however, mediating and moderating factors, and any causal effect, have been neglected. The paired group comparison SEMs for the AD + HY, AD-HY, and control groups all revealed a pathway relationship in which parental bonding affected personality characteristics, personality characteristics affected mental health condition, and mental health condition affected the development of hyperventilation or adjustment disorder. More specifically, with respect to parental bonding, males with $\mathrm{AD}-\mathrm{HY}$ perceived less care from their fathers than those with $\mathrm{AD}+$ $\mathrm{HY}$ and the controls, and males with $\mathrm{AD}+\mathrm{HY}$ perceived more maternal protection than those with $\mathrm{AD}-\mathrm{HY}$ and the controls. Although participants with $\mathrm{AD}-\mathrm{HY}$ and those with $\mathrm{AD}+\mathrm{HY}$ were both more neurotic and less extroverted than the controls, those with AD-HY were even more neurotic and less extroverted than those with $\mathrm{AD}+\mathrm{HY}$. The two groups with adjustment disorder did not differ in their mental health condition; both showed worse mental health than the controls.

The pathway relationship in which parental bonding affected personality characteristics, which in turn affected mental health condition and the development of hyperventilation syndrome or adjustment disorder, is consistent with previous studies on hyperventilation and adjustment disorders $[1,14,18]$. Parental emotional neglect is often related to psychiatric disorder [31]. In addition, the present study found that maternal overprotection increased the risk of hyperventilation syndrome, and less paternal care increased the risk of adjustment disorder. Previous studies have also found that hyperventilation is associated with maternal attachment and premorbid personality [14]; more specifically, maternal attachment has been found to play a unique role in male adjustment disorder with hyperventilation syndrome [14]. This can be understood easily, because maternal attachment is related to the development of problems with self-esteem and behavior, particularly maladjustment behavior $[1-3,14]$, and might be linked indirectly to clinical diagnoses of mental health problems [32].

Attachment style is an important factor in understanding the particular ways in which individuals feel and react when stressed by illness, and is important when assessing the utilization of healthcare [33,34]. With regard to the finding that less paternal care increased the risk of adjustment disorder, previous studies have also found that negative parental attachment is related negatively to the individual's functional morbidity, such as the inability to cope with daily stress, and problems with adjustment and social skills [35,36]. The impact of high parental control and low care tends to increase mental health problems and distress, and such individuals might experience difficulties in interacting with the environment [36-40]. Therefore, dysfunctional parenting is one of the main influences on individual personality traits and the ability to adjust [1-3]. A previous study found that adolescents who had poor communication with their fathers showed more aggressive behavior toward authority in school and had more difficulty in adjusting [41]. When these males enter military service, they are within a predominantly male environment, including their superiors. The experience of poor paternal care might be projected onto these superiors, thus augmenting the adjustment problem.

Interestingly, although high neuroticism and low extroversion were found to increase the risk of adjustment disorder or hyperventilation syndrome, individuals with $\mathrm{AD}-\mathrm{HY}$ showed even greater neuroticism and less extroversion than those with AD $+\mathrm{HY}$. Extroversion had only an indirect effect on individuals with $\mathrm{AD}+\mathrm{HY}$ when compared with the controls. Several studies have demonstrated that neuroticism and introversion might increase the risk of mental disorders such as anxiety, depression, and maladaptive behaviors $[1-3,42,43]$. The present study has highlighted the difference in severity between hyperventilation syndrome and adjustment disorder.

Few studies have investigated the differences between adjustment disorder and hyperventilation syndrome; however, criteria to assist in the differential diagnosis are required. Our study compared individuals with $\mathrm{AD}-\mathrm{HY}$, those with $\mathrm{AD}+\mathrm{HY}$, and controls, and identified 
differences among these three groups with respect to parental bonding, personality characteristics, and mental health. Self-report measures were used for the study, which might have resulted in problems of recall bias in terms of the rating of parental attachment, and this could have influenced the results. However, studies have demonstrated that the PBI has acceptable reliability and validity [22,23]. Furthermore, participant reports of parental behavior have shown a significant association with independent reports [44,45], and twin studies have also shown a high correlation in the rating of parents $[45,46]$. It is thought that attachment insecurity is a determinant of physical health throughout the lifespan $[19,20]$. In the present study, although the PBI was used to measure parental attachment, it does not assess attachment style specifically and this might be a limitation in the current study. Hence, a more in-depth assessment of attachment, using specific self-report questionnaires or the Adult Attachment Interview, should be considered for future studies.

\section{Conclusions}

The study showed that, although some patients with hyperventilation syndrome demonstrated symptoms of adjustment disorder, different predisposing factors were found between the two groups of patients with respect to parental bonding and personality characteristics. Patients with AD-HY perceived a greater degree of paternal care, and those with $\mathrm{AD}+\mathrm{HY}$ perceived a greater degree of maternal overprotection. Those with $\mathrm{AD}-\mathrm{HY}$ also showed a higher degree of neuroticism and less extroversion than those with $\mathrm{AD}+\mathrm{HY}$, although both had poorer mental health than the controls. In addition, the comparison of the $\mathrm{AD}+\mathrm{HY}$ group with the controls using SEM yielded high variances of $66 \%$ and $55 \%$. With adjustment for age, sex, and level of education, this finding is potentially important for the development of early intervention and prevention programs for hyperventilation syndrome and adjustment disorder. Further studies are required to determine whether there is a gender difference in the etiology of hyperventilation syndrome and adjustment disorder, and thus whether this model can be generalized to female patients with hyperventilation syndrome or adjustment disorder.

\section{Competing interests}

All authors have no conflict of interest to declare.

\section{Acknowledgements}

This study was supported by a grant (number 9432) from the Medical Affairs Bureau, Ministry of National Defense, Taiwan. In addition, the authors would like to acknowledge all of the researchers who assisted in this study.

\section{Author details}

'Songde Branch, Taipei City Hospital, Taipei, Taiwan. ${ }^{2}$ Department of Psychiatry, National Defense Medical Center, Taipei, Taiwan. ${ }^{3}$ Department of Psychiatry, Kaohsiung Armed Forces General Hospital, Kaohsiung, Taiwan.
${ }^{4}$ Calo Psychiatric Center, Pingtung County, Taiwan. ${ }^{5}$ Department of Psychiatry, Kai-Suan Psychiatric Hospital, Kaohsiung, Taiwan. ${ }^{6}$ Department of Neurology, Kaohsiung Medical University, Kaohsiung, Taiwan.

\section{Authors' contributions}

FWL contributed to the conceptual design of the study and modified the manuscript. THL participated in the conceptual design, collected the data, data analysis of the study, and drafted the manuscript. MFH interpreted the data. All authors read and approved the final manuscript.

Received: 3 April 2011 Accepted: 6 June 2012

Published: 6 June 2012

\section{References}

1. Lung FW, Lee FY, Shu BC: The relationship between life adjustment and parental bonding in military personnel with adjustment disorder in Taiwan. Mil Med 2002, 167:678-682.

2. Lung FW, Lee FY, Shu BC: The premorbid personality in military students with adjustment disorder. Mil Psychol 2006, 18:77-88.

3. Lung FW, Lin TJ, Lu YC, Shu BC: Personal characteristics of adolescent prostitutes and rearing attitudes of their parents: a structural equation model. Psychiatry Res 2004, 125:285-291.

4. Parker G: Parental overprotection: a risk factor in psychosocial development. New York: Grune \& Stratton; 1983

5. Parker G: The parental bonding instrument. Soc Psychiatry Psychiatr Epidemiol 1990, 25:281-282.

6. Russek LG: Positive perceptions of parental caring are associated with reduced psychiatric and somatic symptoms. Psychosom Med 1998, 60:654-657.

7. Russek LG, Schwartz GE: Perceptions of parental caring predict health status in midlife: A 35-year follow-up of the Harvard Mastery of Stress Study. Psychosom Med 1997, 59:144-149.

8. Xia G, Qian M: The relationship of parenting style to self-reporting style to self-reported mental health among two subcultures of Chinese. J Adolesc 2001, 24:251-260.

9. Folgering $\mathrm{H}$ : The pathophysiology of hyperventilation syndrome. Monaldi Arch Chest Dis 1999, 54:365-372.

10. DaCosta TM: On irritable heart: A clinical study of a form of functional cardiac disorder and its consequences. Am J Med Sci 1871, 61:17-52.

11. Robinson DP, Greene JW, Walker LS: Functional somatic complaints in adolescents: relationship to negative life events, self-concept, and family characteristics. J Pediatr 1988, 113:588-593.

12. Herman SP, Stickler GB, Lucas AR: Hyperventilation syndrome in children and adolescents: long-term follow-up. Pediatrics 1981, 67:183-187.

13. Gregory J, Magarian MD: Hyperventilation syndromes: Infrequently recognized common expressions of anxiety and stress. Medicine 1982, 61:219-236

14. Shu BC, Chang YY, Lee FY, Tzeng DS, Lin HY, Lung FW: Parental attachment, premorbid personality, and mental health in young males with hyperventilation syndrome. Psychiatry Res 2007, 153:163-170.

15. American Psychiatric Association: Diagnostic and statistical manual of mental disorders. 4th edition. Washington, DC: American Psychiatric Association; 1994.

16. Sampang JA: Adjustment disorder with depressed mood: A review of diagnosis and treatment. Adv Nurse Pract 2003, 11:51-54.

17. Snyder S, Strain JJ, Wolf D: Differentiating major depression from adjustment disorder with depressed mood in the medical setting. Gen Hosp Psychiatry 1990, 12:159-165.

18. Chen PF, Chen CS, Chen CC, Lung FW: Alexithymia as a screening index for male conscripts with adjustment disorder. Psychiatr Q 2010, 82:139-150

19. Maunder RG, Hunter JJ: Attachment and psychosomatic medicine: Developmental contributions to stress and disease. Psychosom Med 2001, 63:556-567.

20. Maunder RG, Hunter Jj: Attachment relationships as determinants of physical health. J Am Acad Psychoanal Dyn Psychiatry 2008, 36:11-32.

21. World Health Organization: The ICD-10 classification of mental and behavioral disorders: Diagnostic criteria for research. Geneva: World Health Organization; 1993.

22. Parker G, Tupling H, Brown LE: A Parental Bonding Instrument. Br J Med Psychol 1979, 52:1-10. 
23. Shu BC, Lo WJ, Lung FW: The reliability and validity of a Chinese Version of the Parental Bonding Instrument. Nurs Res 1999, 7:479-489.

24. Eysenck HJ, Eysenck SBG: Manual for the Eysenck Personality Questionnaire. London: Hodder and Stoughton; 1975.

25. Lu L: University transition: Major and minor life stressors, personality characteristics and mental health. Psychol Med 1994, 24:81-87.

26. Cheng TA, Williams P: The design and development of a screening questionnaire (CHQ) for use in community studies of mental disorders in Taiwan. Psychol Med 1986, 16:415-422.

27. Goldberg DP: Manual of the General Health Questionnaire. Windsor, UK: NFER-Nelson; 1978.

28. Goldberg D, Williams P: A user's guide to the General Health Questionnaire. Windsor, UK: NFER-Nelson; 1988.

29. Cheng TA, Wu JT, Chong MY, Williams P: Internal consistency and factor structure of the Chinese Health Questionnaire. Acta Psychiatr Scand 1999, 82:304-308

30. Chong MY, Wilkinson G: Validation of 30- and 12- item versions of the Chinese Health Questionnaire (CHQ) in patients admitted for general health screening. Psychol Med 1989, 19:495-505.

31. Young R, Lennie S, Minnis H: Children's perceptions of parental emotional neglect and control and psychopathology. J Child Psychol Psychiatry 2011, 52:889-897.

32. Overbeek G, Ten Have M, Vollebergh W, de Graaf R: Parental lack of care and overprotection: Longitudinal associations with DSM-III-R disorders. Soc Psychiatry Psychiatr Epidemiol 2007, 42:87-93.

33. Ciechanowski PS, Walker EA, Katon WJ, Russo JE: Attachment theory: a model for health care utilization and somatization. Psychosom Med 2002. 64:660-667.

34. Hunter JJ, Maunder RG: Using attachment theory to understand illness behavior. Gen Hosp Psychiatry 2001, 23(4):177-182.

35. Booth A, Johnson DR, Granger DA, Crouter AC, McHale S: Testosterone and child and adolescent adjustment: the moderating role of parent-child relationships. Dev Psychol 2003, 39:85-98.

36. Valiente C, Fabes RA, Eisenberg N, Spinrad TL: The relations of parental expressivity and support to children's coping with daily stress. J Fam Psychol 2004, 18:97-106.

37. Duggan C, Sham P, Minne C, Lee A, Murray R: Quality of parenting and vulnerability to depression: results from a family study. Psychol Med 1998, 28:185-191.

38. Gittleman MG, Klein MH, Smider NA, Essex MJ: Recollections of parental behaviour, adult attachment and mental health: mediation and moderating effects. Psychol Med 1998, 28:1443-1455.

39. Sato T, Sakado K, Uehara T, Narita T, Hirano SK, Kasahara Y: Dysfunctional parenting as a risk factor to lifetime depression in a sample of employed Japanese adults: evidence for the 'affectionless control' hypothesis. Psychol Med 1998, 28:737-742.

40. Stein D, Williamson DE, Birmaher B, Brent DA, Kaufman J, Dahl RE, Perel JM, Ryan ND: Parent-child bonding and family functioning in depressed children and children at high risk and low risk for future depression. J Am Acad Child Adolesc Psychiatry 2000, 39:1387-1395.

41. Ochoa GM, Lopez EE, Emler NP: Adjustment problems in the family and school contexts, attitude towards authority, and violent behavior at school in adolescence. Adolesence 2007, 42:779-794.

42. Bramsen I, Dirkzwager AJE, Ploeg HM: Predeployment personality traits and exposure to trauma as predictors of posttraumatic stress symptoms: A prospective study of former peacekeepers. Am J Psychiatry 2000, 157:1115-1119.

43. Hough LM, Oswald FL: Personnel Selection: looking toward the future - remembering the past. Annu Rev Psychol 2000, 51:631-664

44. Parker G: Parental reports of depressives. An investigation of several explanations. J Affect Disord 1981, 3:131-140.

45. Reti IM, Samuels JF, Eaton WW, Bienvenu OJ III, Costa PT Jr, Nestadt G: Influences of parenting on normal personality traits. Psychiatry Res 2002, 111:55-64.

46. Parker $\mathrm{G}$ : Validating an experiential measure of parental style: the use of a twin sample. Acta Psychiatr Scand 1986, 73:22-27.

doi:10.1186/1471-244X-12-56

Cite this article as: Lung et al:: Parental bonding in males with adjustment disorder and hyperventilation syndrome. BMC Psychiatry 2012 12:56.

\section{Submit your next manuscript to BioMed Central and take full advantage of:}

- Convenient online submission

- Thorough peer review

- No space constraints or color figure charges

- Immediate publication on acceptance

- Inclusion in PubMed, CAS, Scopus and Google Scholar

- Research which is freely available for redistribution 